\section{What's wrong with ward rounds?}

\author{
John Launer
}

If you have ever been a hospital in-patient, you will know what it means to look forward to ward rounds and to fear them at the same time. On the one hand, you lie there hoping for the doctors to come round because you will hear news of your progress, and perhaps whether you can go home. On the other hand, you almost certainly know from experience that the encounter with doctors will be brief and frustrating, with little opportunity to ask all the questions you wanted, no privacy, and the annoyance of having half a dozen strangers around your bed who might well be looking bored and in a hurry to move on. It is practically impossible to get a focussed conversation for 10 min or more, discussing complex choices about your care, and with other family members present if you wish-all of which you may be accustomed to doing with your own general practitioner.

Ward rounds are a mixed blessing for doctors too. In theory, they provide a regular case review of every patient, an opportunity to teach and learn, and a way of exchanging knowledge and ideas among the professional team. However, in practice they can turn into an unthinking ritual, especially at the end when everyone is tired, or if there is pressure to discharge patients. Ward rounds are often too rushed for any real teaching to take place, and in the worst instances they allow stressed consultants to lambast their juniors publicly for things they forgot to do. Although they ought to provide a chance for doctors and nurses to communicate with each other about everyone's care, the tradition of including a nurse on every round has broken down in many places because people are so busy. In reality, doctors may often find ward rounds just as disappointing as patients do.

Given the centrality of ward rounds in patient care and medical decision-making, it seems extraordinary that people have given so little attention in past to running them effectively and ethically. This is changing, and the Royal Colleges of Physicians and of Nursing have now issued guidance for best practice on ward rounds. ${ }^{1}$ One of the authors of the guide is a physician in

Correspondence to Dr John Launer, Faculty Development, Shared Services, Health Education, Stewart House, 32 Russell Square, London WC1B 5DN, UK: john.launer@southlondon.hee.nhs.uk the south of England called Gordon Caldwell. He has probably spent more time thinking, writing and speaking about the failings of ward rounds, and their unrealised potential, than anyone else in the country. His main focus has been on the risks to patient safety that occur on every single ward round, and on ways of reducing these, although he is also concerned about issues of communication and patient involvement. Writing in the BMJ in 2010, Caldwell pointed out that complex decisions about patients with multiple disorders are often made on the hoof, in suboptimal conditions, with missing information, and with frequent distractions. ${ }^{2}$

\section{CONSIDERATIVE CHECKLIST}

Caldwell's most important contribution to improving ward rounds has been a systematic approach called the 'considerative checklist', covering everything significant that should be considered in every patient. ${ }^{3}$ A different member of the team takes responsibility for administering the check list on every round. This could be a foundation year doctor, a registrar, nurse, medical student or consultant. The value of check lists is well known in fields like operative surgery, ${ }^{4}$ and they often exist in rudimentary form on medical rounds, for example by including a box on every drug chart to assess the risk of deep vein thrombosis.

Working on the principle that there are many simple and common errors can cause life-threatening harm, Caldwell's check list includes a wide range of 'process' measures including a record of if a nurse was present at the bedside, hand hygiene, whether introductions took place, if the patient was identified from their wristband, and whether the doctors inquired about pain, eating, drinking and bowel function as well as checking cannulas and catheters. He also ensures a scribe sums up after leaving the bedside so there is a shared understanding of patient's problems and the action plan.

In addition to the main 'considerative' list, there is a system for assessing drug charts, called, 'check and correct', which involves another member of the team reviewing a list of items including whether everything on the drug chart is clear and unambiguous, all drugs are prescribed in unmistakable units (eg, 'units' not 'U'), and that the main prescriber's name has been entered in capitals with both their GMC and bleep numbers. ${ }^{5}$ To avoid this becoming a mindless exercise in ticking boxes, whoever does the checking is praised for every error they pick up. Not surprisingly, the exercise rarely passes without such errors being noticed. Although each might be apparently trivial, any one of them might have led to a significant health risk if undetected.

Caldwell is a great advocate of holding a preliminary 'board round', where patients are reviewed prior to going to see them on the ward, preferably carried out in a quiet and comfortable room where it is possible for the team to think and talk. Quite aside from the clinical benefits of such group reflection, these kinds of board rounds have been shown to have a particular value in teaching. ${ }^{6}$ A review at the end of the round covers who will go back to speak with the patient and family, as well as contacting other professionals like the physiotherapist or pharmacist. For teaching purposes, trainees give regular feedback on each other's performance including their case presentations, clinical judgement and rapport with the patient.

\section{SAFE AND ETHICAL}

If this all these systems sound obsessional and time-consuming, I can say from direct observation that neither is the case. What happens instead is something that is orderly, transparent, safe, and ethical, and avoids wasting time with unfocussed chat. One part of the process I found particularly impressive is that everyone commits themselves explicitly at the beginning of the round to observe everybody else's words and actions, and to speak up at once if they have any concerns. The contributions of everyone from the most junior medical student to the most experienced registrar are listened to. The discussion models the importance of each person taking their clinical and moral responsibility seriously.

As Caldwell has pointed out in a recent presentation, ${ }^{7}$ ward rounds represent the 'main production line' of medicine but nevertheless remain 'underappreciated, undervalued and underdeveloped.' In spite of their quantity and cost (an estimated $30000 \mathrm{~h} /$ day of staff time in the NHS in England, costing up to $£ 18$ million), managers feel they do not need to intervene in how they are run for many reasons but mainly because they regard them as 'ordinary and unremarkable', or 'private and confidential'. Managers and doctors alike tend to believe that the process of diagnosis is easy, even though up to 400 decisions about investigations and interventions may 
be made on a single ward round-often on the basis of inadequate information because results are not available, key people cannot be contacted, and everything is done unsystematically.

Like Gordon Caldwell, I have been arguing for many years for improvements in the way ward rounds are conducted, and even for their replacement by more effective and patient-centred means of decision-making. ${ }^{8}$ This includes allocating most of the time to 'board rounds' followed by assigning the most senior doctors to deal with the most critically ill or anxious patients while others attend to the less urgent ones, thus providing each patient and family with more quality time to pose their questions and address their concerns. As Caldwell says, we need to start regarding ward rounds not as 'ordinary and unremarkable' but in need of our focussed attention just as much as the most expensive technology or complex drug treatment. The benefits to quality, safety, effectiveness, efficiency and staff satisfaction would be enormous, and patients would be hugely happier as well.

\section{Competing interests None.}

Provenance and peer review Commissioned; internally peer reviewed.

To cite Launer J. Postgrad Med J 2013;89:733-734.

Postgrad Med J 2013;89:733-734.

doi:10.1136/postgradmedj-2013-132472

\section{REFERENCES}

1 Royal College of Physicians and Royal College of Nursing. Ward rounds in medicine: principles for best practice. London: Royal College of Physicians, 2012.
2 Caldwell G. What is the main cause of avoidable harm to patients? BMJ 2010;341:558.

3 Herring R, Desai T, Caldwell G. Quality and safety at the point of care: how long should a ward round take? Clin Med 2011:11:20-2.

4 Gawande A. The checklist manifesto: how to get things right. London: Profile Books, 2009.

5 Caldwell G. Real time 'Check and Correct' of drug charts on ward rounds-a process for improving doctors' habits in inpatient prescribing. Pharm Manag 2010;26:3-9.

6 Carley S, Morris H, Kilroy D. Clinical teaching in emergency medicine: the board round at Hope Hospital emergency department. Emerg Med J 2007;24:659-61.

7 Caldwell G. The importance of ward rounds. Presentation to NHS Emergency Care Intensive Support Team, 17 October 2013. https://www.dropbox.com/s/ tzep6wa8sw4ik0b/The \%20Importance\%20of\%20Ward $\% 20$ Rounds\%20plus\%20appendices.pdf (accessed 2 Nov 2013).

8 Launer J. Doing the rounds. QJM 2003;96: $321-2$. 